\title{
Investigating Stability and Change in Substance Use and Criminal Activity Using a Synthesized Longitudinal Modeling Approach ${ }^{1}$
}

\begin{abstract}
Christopher J. Sullivan, Alex R. Piquero
The application of career perspectives in substance use and crime research has emphasized both stability and change. Curran and Bollen (2001) recently developed an analytic approach, the autoregressive latent trajectory model (ALT), which permits the analysis of both persistent individual differences in behavioral trends and stage-specific direct relationships. The present study utilizes this modeling approach with a sample of 524 offenders released from the California Youth Authority followed over seven years in early adulthood. The results of the analytic process suggest that the ALT model fit the data well. Comparatively, that model fit better than the autoregressive or $L G C$ specifications and provides more information. The ALT model provides estimates that are relevant in understanding key parameters of the substance use and criminal career frameworks-both singly and jointly. The results of this investigation are then considered from the standpoint of future methodological development and substantive theoretical considerations of longitudinal patterns of substance use and crime.
\end{abstract}

\section{INTRODUCTION}

The relationship between substance use and criminal behavior is one of the more consistent findings in the social sciences (Chaiken \& Chaiken, 1982, 1990).

Christopher J. Sullivan is Assistant Professor in the School of Criminal Justice at the University of Cincinnati. He received his doctorate at the Rutgers University School of Criminal Justice in 2005. His research interests include developmental criminology, juvenile delinquency and prevention policy, and research methodology and analytic methods. His recent work has appeared in Criminology, Journal of Research in Crime and Delinquency, British Journal of Criminology, Journal of Quantitative Criminology, and the Journal of Experimental Criminology. Alex R. Piquero is a Professor in the College of Criminology \& Criminal Justice at Florida State University, and Co-Editor of the Journal of Quantitative Criminology. His research interests include criminal careers, quantitative research methods, and criminological theory. He is past Executive Counselor with the American Society of Criminology, and past recipient of the American Society of Criminology's Young Scholar and E-Mail Mentor of the Year Award, as well as the recipient of the University of Florida's College of Arts \& Sciences Teacher of the Year Award. 


\section{Sullivan, Piquero}

In recent years, the use of a "career" paradigm has led to gains in understanding the development of both behaviors (Hser, Longshore, \& Anglin, 2007; Hunt, 1997; Piquero, 2008). Generally, a "career paradigm" frames the empirical study of substance use and criminal activity around the onset, persistence, and desistance in those behaviors over the life course. Chaiken and Chaiken (1990) suggest that this is a solid framework for considering the relationship between drug use and crime as well (see also Farabee, Joshi, \& Anglin, 2001; Hser, Anglin, Grella, Longshore, $\&$ Prendergast, 1997). This "career" orientation also reflects the need to consider analysis of individuals over time, as opposed to just variables, in understanding the drug/crime relationship (Da Agra, 2002). Person-centered approaches are believed to provide greater depth in portraying developmental patterns and their underlying influences (Bergman \& Magnusson, 1997), which sets the stage for the use of interventions focused on fostering within-individual change (Farrington, 2005).

There are now rich bodies of literature in both the crime and substance use fields that take a career perspective. Research on offending involves consideration of concepts such as onset, persistence, and desistance across the life-course (Piquero, Farrington, \& Blumstein, 2003, 2007). In the study of substance use, there is an understanding that use/addiction is frequently a chronic condition where users might go through initiation, cessation, relapse, and abstinence stages over time (Dennis, Foss, \& Scott, 2007; Scott, Foss, \& Dennis, 2005; Shaw, 2002). Hser and colleagues (2007) have recently pointed to parallel career parameters that can be used to frame longitudinal patterns in both substance use and criminal activity (see also Hser et al., 1997). In particular, the process of criminal desistance is thought to be similar to that of drug cessation. Empirically, using growth mixture modeling, Chassin, Flora, and King (2004) found a series of alcohol and drug use trajectory groups fairly similar to many of those observed in the study of crime, again suggesting parallels between the two.

The relationship between substance use and crime has been demonstrated to be "chronic" as opposed to acute (Chaiken \& Chaiken, 1982) and appears to be part of a general, deviant lifestyle (Nurco, Hanlon, Kinlock, \& Duszynski, 1988; Osgood, Johnston, O'Malley, \& Bachman, 1988), suggesting the need to examine their joint patterns over time (Clayton \& Tuchfeld, 1982). The current study examines the substance use-crime relationship over a period of several years in a sample of serious, youthful offenders. It applies a bivariate model that accounts for autoregressive, state-dependent effects and the underlying latent growth of the behaviors in question. This is important as, recently, there has been some discussion around the limitations of growth, or trajectory, models in fully accounting for substantively interesting aspects of longitudinal behavioral processes (Osgood, 2005; Raudenbush, 2005; Sampson \& Laub, 2005, 2005b). 


\section{A Synthesized Model of Substance Use and Crime Trends}

\section{The Career Framework in Substance Use and Crime}

Early work in developmental, life-course criminology laid out a number of key components of criminal careers (Blumstein, Cohen, Roth, \& Visher, 1986), and has led to a variety of studies examining criminal behavior as it unfolds over time (LeBlanc \& Loeber, 1998; Loeber \& LeBlanc, 1990; Piquero et al., 2003; Piquero, 2008), and a smaller number devoted to how these careers wind down or stop (Laub \& Sampson, 2001, 2003). Hser and colleagues $(1997,2007)$ have also presented some key components of drug use and treatment careers. A number of career-centered studies have emerged in that field as well (Anglin \& Speckart, 1986; Dennis et al., 2007; Dennis, Scott, Funk, \& Foss, 2005; Hser, Hoffman, Grella, \& Anglin, 2001; Hunt, 1997; Nurco, Cisin, \& Mitchell, 1981; Prendergast, Huang, \& Hser, 2008; Scott et al., 2005). Hunt (1997) indicates that the "career paradigm" in drug research has produced rich portraits of the lives of serious substance users and Hser et al. (2007) point to its future potential for organizing research relevant to policy and programming.

Drug use can prolong or accelerate an offending career (Chaiken \& Chaiken, 1990; Hussong, Curran, Moffitt, Caspi, \& Carrig, 2004) and desistance from crime may co-occur with abstinence from drugs and/or alcohol. A good deal of early research found that offending levels are greater during periods of substance abuse (Anglin \& Speckart 1986; Ball, Rosen, Flueck, \& Nurco., 1981; McGlothlin, Anglin, \& Wilson, 1978; Nurco et al., 1988). Ball et al. (1981) found that periods of heroin addiction were punctuated by instances of greater criminal behavior as well. This, coupled with their finding that a very small minority of their addict sample did not engage in criminal behavior during their time at risk, again suggests a substantial relationship between drug use and criminal activity. Anglin and Speckart (1986) found differences in mean levels of drug use over time, suggesting instability across the drug-use career. They also found that the prevalence of property crime and dealing were strongly related to use during high use periods and were not as prevalent during periods of lower drug involvement. Overall, this work suggests that the relationship between drug use and crime is a symbiotic one where, over time, one affects the other (Da Agra, 2002).

Understanding continuity and discontinuity and their origins is a key focus in the study of individual criminal behavior (Piquero et al., 2003) and substance use (Hser et al., 2007). In a pioneering study of antisocial behavior, Robins (1978) provided early insight on the relationship between past and present states, finding that the antisocial adults in her cohorts were virtually always similarly disposed as children. Heckman (1981) proposed two means by which behavioral continuity might be properly understood. First, individuals may simply differ in their propensity to participate in a particular behavior, and that enduring feature continues to manifest 
itself over time - suggesting apparent stability. Second, one might posit that past experience has a causal effect on later behavior by altering future preference for that activity or impacting some other circumstances related to its occurrence (e.g., relationships with family). Thus, explanatory frameworks for longitudinal patterns of antisocial behavior typically take on one of two forms: population heterogeneity or state dependence. ${ }^{2}$

Picking up on this theme, Nagin and Paternoster (1991) point out that the relationship between past and present criminal behavior is a regularly observed phenomenon. On this score, both Heckman (1981) and Nagin and Paternoster $(1991,2000)$ use an "urn scheme" to portray the distinctions between these two explanations of continuity in behavior. Nagin and Paternoster (1991, p. 167-168) set up a hypothetical scenario where individuals are given urns with (a) differing colors (red, blue) of balls and (b) differing numbers of balls. The red balls might represent "criminal activity" or "substance use" and their relative proportion in each person's urn reflects their initial, enduring likelihood of engaging in such behavior. In the first scenario, representing population heterogeneity, individuals are assigned different proportions of red and blue balls and that distribution remains constant, reflecting the propensity of each individual. Each individual then draws balls with replacement over time so that the relative probability of drawing a red one remains the same. In this case, the probability of someone drawing a red ball at any particular time point is attributable to their initial distribution of balls in the urn (i.e., there is an unfolding of that initial propensity over time). In the second scenario, individuals are initially assigned urns with the same proportion of red to blue balls, meaning that, at least at the outset, all have equal propensity for offending or substance use. From there, individuals again draw balls with replacement over time. In this scheme, however, drawing a red ball leads to its replacement with more red balls. This, of course, means that drawing a red ball (i.e., committing a crime) increases the likelihood of doing the same at a later time point, indicating a state-dependent effect. Clearly, one could also envision a "mixed" scenario where individuals start out with different urn compositions (i.e., propensities) and also have different degrees of replacement of the composition of balls over time (i.e., state-dependent effects). Additionally, there may be conditions that affect the initial distribution of red balls or their process of selection at each stage.

The evidence now suggests that both population heterogeneity and statedependence perspectives are necessary, so there is a need to consider analytic models that are useful in informing further theoretical elaboration pertaining to substance use and criminal careers (Laub \& Sampson, 2003; Paternoster \& Brame, 1997). In addition to individual propensities that underlie the developmental process, it is believed that there are important life events and social factors that influence behavior 


\section{A Synthesized Model of Substance Use and Crime Trends}

over time (Horney, Osgood, \& Marshall, 1995; Hser et al., 2007; Laub, Nagin, \& Sampson, 1998; Osgood, 2010; Piquero, MacDonald, \& Parker, 2002; Piquero et al., 2003; Scott et al., 2005).

Recognizing the importance of combining persistent heterogeneity/statedependence perspectives with added attention to the type and role of life events in influencing behavior, extant theories have been modified and/or developed to account for these now well-established findings. A principal example is Sampson and Laub's (1993) age-graded, informal social control theory, which has been primarily applied to the study of crime (for an application to substance use, see Nielsen, 1999). Briefly, their theory accounts for the relationship between prior and future antisocial behavior (persistent heterogeneity), while also allowing for life-course transitions (state dependence) to alter offending pathways. In this regard, Sampson and Laub allow for both stability and change in patterns of offending over the life course. Hser et al. (2007) identified this theory as a potentially useful explanatory framework in considering substance use across the life-course. In reconciling these perspectives and providing some means of further integration, it is necessary to consider expanding the analytic framework from which these issues are examined.

\section{The Current Study}

As Bushway, Brame, and Paternoster (1999) point out, a critical test of the population heterogeneity, state dependence, and mixed explanations for continuity in offending requires an analytic approach that can assess the effects of dynamic influences after adjustment for individual differences in behavioral propensity. At the same time, recent reviews of the evidence for these two explanations (Nagin \& Paternoster, 2000) and the framing of career perspectives in substance use (Hser et al., 2007) and criminal behavior (Piquero et al., 2003) suggest support for both perspectives, meaning that it is important to move beyond simply "controlling" for one or the other to using analytic approaches that substantively address both.

The autoregressive, latent trajectory (ALT) model is a flexible framework that considers the relationship among longitudinal, repeated measures as a function of an underlying process of growth, as well as a set of time-specific, lagged effects (Curran $\&$ Bollen, 2001). This synthesized approach allows for an assessment of the presence of an underlying latent growth process in behavior-over and above the effects of that behavior at previous time points. At the same time, state-dependent effects can be estimated across several time periods while accounting for an underlying, enduring growth process in behavior. As a result, the model captures effects associated with both state-dependence and population heterogeneity explanations of longitudinal patterns in behaviors. The ALT model estimates substantively relevant parameters that allow the two perspectives to be viewed in an integrated fashion to further the 
pursuit of a comprehensive explanatory perspective on longitudinal offending and substance use.

The ALT modeling approach, as applied here, offers a few specific advantages in terms of understanding the nature of longitudinal substance use and criminal behavior. First, several longitudinal time points are used, allowing for an examination of multiple sequential effects that illuminate the previous stage's impact on the behavior at the next (e.g., Time 1 to Time 2) - net of the underlying propensity. Although other approaches, such as a pooled time series analysis, can provide estimates of the magnitude of the effect of previous substance use and offending on later behavior, there is typically only one estimate to inform the understanding of the strength of that influence. The ALT model allows for autoregressive estimates across the span of the panel time series, which can aid in discerning whether the effect is stronger or weaker at particular stages. It is possible, for example, that the effect of prior substance use or offending may dissipate or intensify over time, and estimating the series of effects allows for some consideration of this question. In pooled random and fixed effects models, for example, it is assumed that the effects of covariates are the same over time (Phillips \& Greenberg, 2008). ${ }^{3}$ In the ALT model, looking at several stages provides a triangulated assessment of the consistency of the state-dependent effect.

The ALT model also offers an overall consideration of the average growth trend in the population and its variance. This approach speaks clearly to the notion of how the behavioral propensity manifests itself over time. This is discernible from the growth factors estimated in the latent growth curve portion of the ALT model. Significant variation in the growth factors suggests that there are between-individual differences in substance use and offending patterns. Incorporation of the growth factors also allows for a straightforward consideration of population heterogeneity as an underlying process that impacts behavioral trajectories both at the outset (Intercept) and over time (Slope).

The autoregressive component of the analysis allows for incorporation of potential time-varying influences into the stage-sequential portion of the longitudinal process. The incorporation of relevant time-varying covariates allows for a better understanding of how behavior at one point in time affects key social relationships and, in turn, impacts subsequent behavior. This is important in understanding the types of life events that are believed to be essential in the longitudinal course of substance use (Dennis et al., 2007; Hser et al., 2007; Scott et al., 2005) and offending (Horney et al., 1995; Osgood, 2010; Piquero et al., 2002; Sampson \& Laub, 1993). Also, factors that are expected to influence the overall propensity for certain behavior can be used as regressors in the latent growth curve portion of the model. On the whole, the ALT approach offers a method by which substance 


\section{A Synthesized Model of Substance Use and Crime Trends}

use and offending can be further examined for evidence of both state-dependence and persistent heterogeneity effects in a manner that allows for a fuller substantive understanding of each. ${ }^{4}$

\section{METHOD}

\section{SAMPLE AND MEASURES}

This study utilizes longitudinal data on California Youth Authority (CYA) parolees, which have served as an important resource in other investigations of criminal behavior over the life-course (Haapanen, 1990; Piquero et al., 2001, Piquero, Brame, Mazerolle, \& Haapanen, 2002). Participants were serious offenders released from custody in their late teens or early 20s. Data on criminal offenses were collected from California Department of Justice "rap sheets." A total of 524 male offenders were followed-up for seven years after release. Roughly $48 \%$ of the sample was White, $33 \%$ was Black, and $17 \%$ was Hispanic. On average, these individuals were 18.8 years old $(S D=1.07)$ in the initial year of study.

Crime was measured by examining the offender's official record. The measure utilized here is the natural $\log$ of the number of violent and non-violent crimes committed by the offender in a given year of follow-up. Violent arrests comprised offenses such as murder, rape, and aggravated assault, while non-violent arrests included burglary, receiving stolen property, grand theft, auto theft, and forgery. Substance use was measured for heroin, alcohol, uppers/downers, and mind-altering drugs (e.g., LSD), and was collected from the offender's case file records. Subjects were coded " 1 " if they used and " 0 " if they did not use in a particular year. For the current analysis, an additive variable was created to denote "number of substances used" over the course of the year.

\section{ANALYTIC APPROACH}

An integrated, longitudinal model must capture both the direct effects of past behavior on current substance use and criminal activity and also provide some understanding of their underlying change or stability over time. In short, it must take both a global view of the behavior over time (i.e., longitudinal trajectory) and offer some sense of the specific effects at particular points in that career (i.e., stagesequential estimates). Autoregressive, simplex models allow for the estimation of stage-sequential effects of behavior (Curran \& Bollen, 2001; Jöreskog, 1970; Marsh, 1993). Specifically, in the autoregressive model the true score at a given time point $(t)$ is believed to be a function of the true scores and random error at the time points prior to that (Marsh, 1993). In a series of measurements, however, all effects are presumed to be indirect with the exception of that which immediately precedes $t$ (i.e., $t$-1). In a quasi-simplex model, which is applied here, the score at a particular stage is a function of the influence of the preceding time's value along with random 
error (Bollen \& Curran, 2004; Jöreskog, 1970; Marsh, 1993). Equality constraints on prediction errors may also be set to appropriately capture the repeated measurement process (Jöreskog, 1970). ${ }^{5}$ The autoregressive simplex model is portrayed in Figure la, where the observed scores at each time point $(t)$ are believed to depend on those at the previous stage $(t-1)$, along with some degree of measurement error.

Latent growth curve (or trajectory) models, in contrast to the simplex model, are directed towards an understanding of the underlying process at work in the longitudinally observed behavior of interest (Hancock \& Lawrence, 2006; Singer \& Willett, 2003). This model estimates underlying, latent growth factors that draw on all observed time points (Curran \& Bollen, 2001), allowing individuals to have their own trajectories (i.e., intercept, slope), which are summarized by an estimated sample mean and variance. It also incorporates a covariance estimate for the slope and intercept, which provides a sense of the relationship between the starting point and level of growth in the behavior. This model is portrayed in Figure $1 \mathrm{~b}$, where observed levels of behavior at each time point $(t)$, rather than being directly influenced by the previous level $(t-1)$, are influenced by the latent intercept and slope.

\section{Figure 1. Example of Autoregressive (a) and Latent Growth Curve Models (B)}

(a)

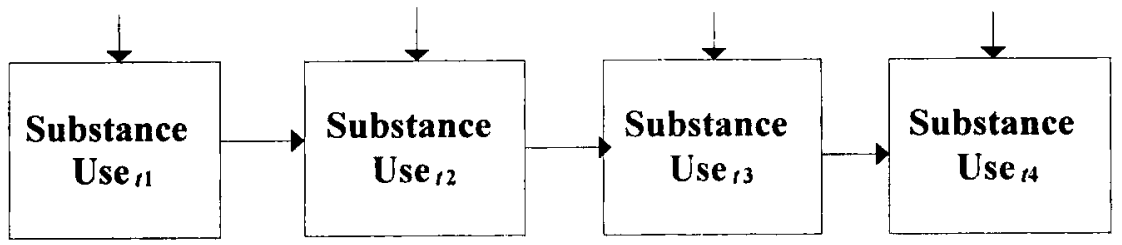

(b)

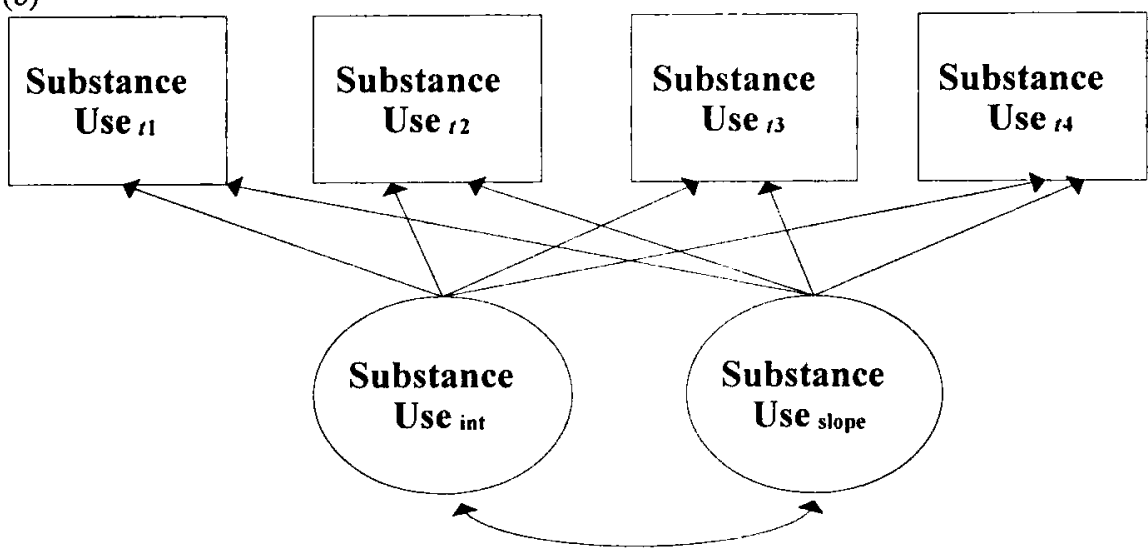




\section{A Synthesized Model of Substance Use and Crime Trends}

A singular focus on one or the other model inhibits a full understanding of longitudinal patterns of behavior. Latent growth curve models do not allow inference about behavior at one stage that predicts the same behavior at subsequent periods (state dependence). Specifically, while such analyses offer a summary that spans the career, they can miss some of the internal workings (i.e., shifts in the shorter term) of those processes. In that way, the potential aggregation of the behavior across a career may potentially become a black-box in which the long-term trends are clear, but the events contributing to them are difficult to elucidate. The latent growth curve model focuses on individual differences in longitudinal trajectories of behavior that illuminate enduring differences in behavioral patterns that are essential in understanding the life course of behavior. The autoregressive model, on the other hand, gives primacy to the fixed effect, lagged relationship of a behavior from one point in time to the next. Still, it is limited in that it does not provide a summary of the overall pattern of behavior as it unfolds over time.

Of late, variants of growth models (e.g., latent class growth analysis or semiparametric, group-based models, growth mixture models) have been applied with increasing frequency in the longitudinal study of substance use (Chassin et al., 2004; Chung, Maisto, Cornelius, \& Martin, 2004; Greenbaum, Del Boca, Darkes, Wang, \& Goldman, 2005; Prendergast et al., 2008) and criminal behavior (Kreuter \& Muthén, 2008; Nagin, 2005; Piquero, 2008). Exclusive reliance on these models in knowledge-building may limit a full examination of the state-dependence and population heterogeneity explanations for behavior in an integrated fashion. Specifically, researchers can view the long-term picture, but not the stage-to-stage effects that may be important in understanding the nature of the longitudinal behavioral process. The latter issue is especially important in framing life course research in both substance use (Hser et al., 2007) and criminal activity (Osgood, 2005).

Fortunately, as Bollen and Curran (2004) indicate, the autoregressive and latent growth curve models need not be considered competitors. In using the Autoregressive Latent Trajectory model (ALT), researchers can study both the underlying trend and time-specific effects in the structural model. The evidence presented above suggests that substance use and criminal behavior provide examples of processes that may be best understood through such analytic integration. ${ }^{6}$ In the ALT model, the autoregressive portion of the model assesses the extent to which substance use or crime at one stage increases the likelihood of the same behavior at a subsequent time point, and the latent growth aspect allows for an understanding of the underlying process as one that unfolds across the career. Curran and Bollen (2001; Bollen \& Curran, 2004) initially applied the model to the longitudinal study of mental health problems and antisocial behavior. Here, it is applied jointly to longitudinal substance 


\section{Sullivan, Piquero}

use and criminal behavior. In doing so, it offers a panoramic view of the career over an extended time span, but also provides a window into shorter periods within those longitudinal trends.

The model estimates the outcome for each person at a given time point $\left(y_{i t}\right)$ as a function of underlying intercept and slope factors $\left(\boldsymbol{\eta}_{\alpha i} \cdot \boldsymbol{\lambda}_{t} \boldsymbol{\eta}_{\beta i}\right.$, respectively) as well as the influence of $y$ at prior stages $\left(\boldsymbol{\rho}_{t, t-1} y_{t, t-1}\right)$ and a time-specific error term $\left(\varepsilon_{i t}\right)$ (Curran \& Bollen, 2001):

$$
y_{i t=} \boldsymbol{\eta}_{a i}+\lambda_{t} \boldsymbol{\eta}_{\beta i}+\boldsymbol{\rho}_{t, t-1} y_{t, t-1}+\varepsilon_{i t}
$$

In this analysis, $y_{i r}$ is the level of substance use or criminal activity at a given time point and $\boldsymbol{\eta}_{\alpha i} ; \boldsymbol{\lambda}_{t} \boldsymbol{\eta}_{\beta i}$ denote random, latent variables reflecting the initial level of the behavior (intercept) and its growth trend (slope) over time. The $\lambda_{t}$ captures the factor loadings for the slope across the repeated measures. Finally, $\rho_{t,-1} y_{t, t-1}$ reflects the autoregressive effect of substance use or crime at one time point on that same behavior at the next observation point. This equation (and the model it captures) suggests that substance use and crime are a function of both an underlying growth process and lagged direct effects of the same behavior at previous time points. Figure 1 provides a visual portrayal of the model as estimated in the present study. The current, joint application of the model also allows for the specification of correlation or regressive effects between substance use and crime at given stages. Additionally, relationships among the latent growth factors (slopes, intercepts) can be estimated and assessed to consider correspondence in their underlying trends.

The present application, in accordance with Bollen and Curran's (2004) specification, treats the initial $y_{\mathrm{t}}$ (Substance Use ${ }_{\mathrm{t}}$, Crime ${ }_{\mathrm{tl}}$ ) as "predetermined" and frees its correlations with the growth factors. This measure is then estimated by an unconditional mean along with deviation from that value. Greene (2003) points out that a variable can be specified as predetermined if it is independent of the later disturbances in the repeated measures. Such variables can then be treated, asymptotically, as if they are exogenous for the purpose of obtaining consistent estimates. The use of the predetermined measures, coupled with the seven data points in the present study, allows for identification of this ALT model. ${ }^{7}$

In the current study, a stepwise approach specifies a series of models reflecting the (a) autoregressive/simplex, (b) latent growth curve, and (c) ALT models. This provides a sense of the fit for the first two models and also allows for consideration of the relative improvement, if any, for the ALT specification. Varying specifications of the relationships between substance use and crime (e.g., cross-lagged, regressive, concurrently correlated) are also considered in the modeling process. All models were estimated using a maximum likelihood procedure in MPlus 5 (Muthén \& 
Figure 2. Bivariate Autoregressive Latent Trajectory (ALT) model for Substance Use and Crime

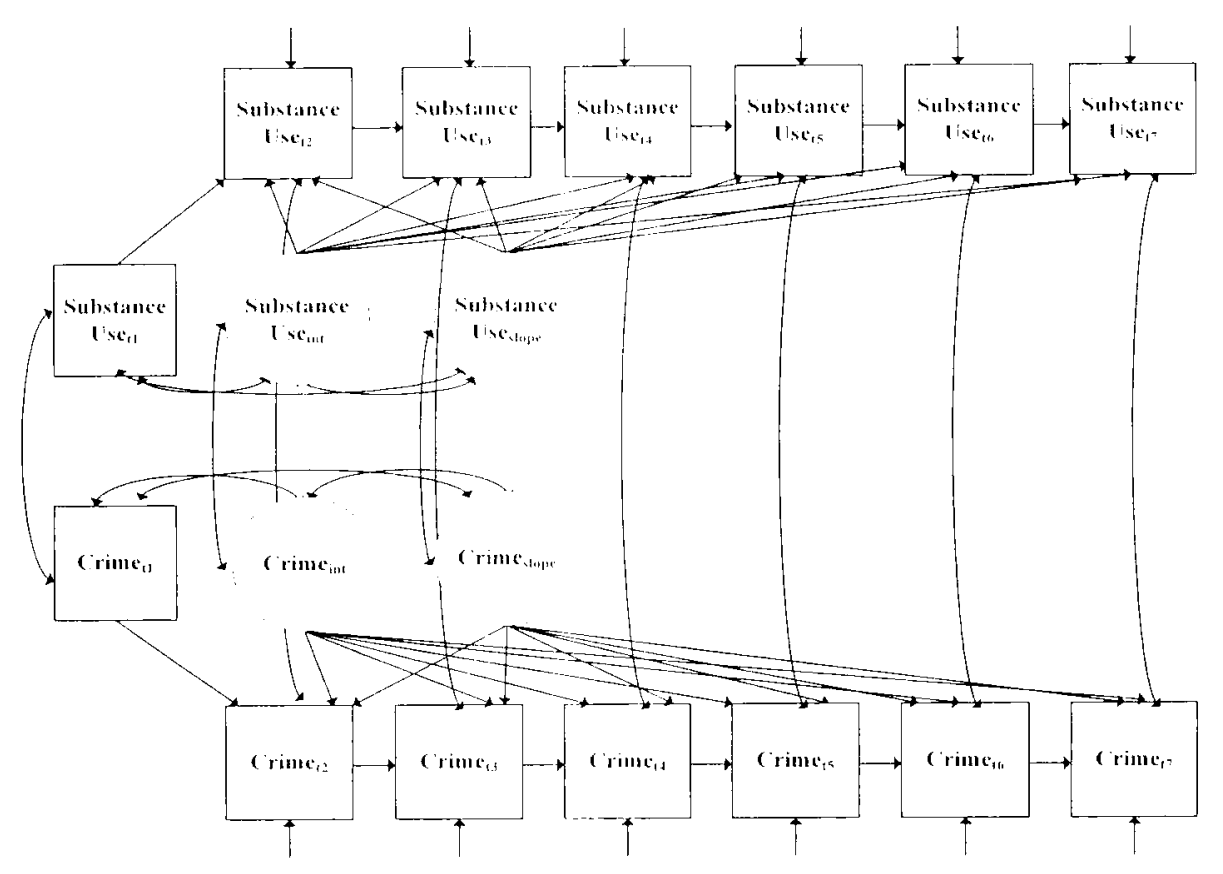

Muthén, 1998-2008). A variety of fit measures were then examined to assess the match of each model to the data. These measures include the Comparative Fit Index $(C F I)$, Tucker-Lewis Index (TLI), Root Mean Square Error of Approximation (RMSEA), and the Standardized Root Mean Square Residual (SRMR) (Hu \& Bentler, 1999). ${ }^{8}$ Cut-offs for good fit for the former two measures (CFI, TLI) are typically above 0.90. It is expected that the values for the latter two measures (RMSEA, SRMR) should fall below 0.05. The Bayesian Information Criterion (BIC), based on the log-likelihood for the specified model (adjusted for complexity), is used to directly assess the difference in fit between models. This index has been found to be substantively useful and demonstrates statistical efficacy in previous studies with similar research questions (Brame, Nagin, \& Wasserman, 2006; Bushway et al., 1999; Nagin, 2005). ${ }^{9}$ Individual parameter estimates are likewise considered in assessing the relative model results. 


\section{Results}

Table 1 presents descriptive statistics for the key study measures and some basic demographic information for the sample. Overall, there was a fairly wide observed range in the yearly offense numbers. Clearly, a number of offenders had zero offenses, but, at the same time, the results suggest a fair degree of variability. For example, standard deviations are high relative to the averages for all years. Also, the ranges for yearly offenses were in the teens and twenties for all years. Individuals averaged between 1.5 (Year 7) and 2.5 (Year 2) offenses per year. For the most part, the mean number of offenses rested around two for the years in this time window. For substance use, these individuals, on average, used more than one substance (of the four) at all stages with a slight climb to Year 5 before a similar decline in Years 6 and 7.

The fit statistics for the estimated models are presented in Table $2 .{ }^{10}$ The ALT model incorporates parameter estimates from both the simplex and LGC specifications. The $B I C$ value for the ALT model was 16810.09 , which is lower than the LGC specification (16905.26) and the AR model (17016.59). The internal fit indices also support the model's fit to the data (Hu \& Bentler, 1999). The CFI and $T L I$ values of 0.99 and 0.98 , respectively, exceed the established cut-off of 0.90 (and even more stringent values of 0.95 ). Additionally, the $S R M R$ and RMSEA

Table 1. Descriptives for Key Study Variables and Sample Sociodemographics $(N=524)$

\begin{tabular}{l|lll}
\hline & Mean & $S D$ & Range \\
\hline Substance Use & & & \\
$N$ Substances Y1 & 1.25 & 1.12 & $0-4$ \\
$N$ Substances Y2 & 1.34 & 1.18 & $0-4$ \\
$N$ Substances Y3 & 1.36 & 1.18 & $0-4$ \\
$N$ Substances Y4 & 1.38 & 1.17 & $0-4$ \\
$N$ Substances Y5 & 1.45 & 1.20 & $0-4$ \\
$N$ Substances Y6 & 1.34 & 1.19 & $0-4$ \\
$N$ Substances Y7 & 1.28 & 1.16 & $0-4$ \\
Crime & & & \\
$N$ Offenses Y1 & 2.38 & 2.71 & $0-23$ \\
$N$ Offenses Y2 & 2.54 & 2.78 & $0-16$ \\
$N$ Offenses Y3 & 2.30 & 2.83 & $0-16$ \\
$N$ Offenses Y4 & 2.12 & 2.73 & $0-14$ \\
$N$ Offenses Y5 & 2.17 & 3.20 & $0-29$ \\
$N$ Offenses Y6 & 1.94 & 2.81 & $0-18$ \\
$N$ Offenses Y7 & 1.55 & 2.47 & $0-19$ \\
& & & \\
\hline Race (White) & .485 & & $16-22$ \\
Age Y1 & 18.8 & 1.07 & \\
\hline
\end{tabular}




\section{A Synthesized Model of Substance Use and Crime Trends}

values are below 0.05 , which also indicates good fit for the ALT model. Overall, considering the internal model fit indices (i.e., comparing model to data) and the $B I C$ (i.e., comparing model to model), it appears that the ALT clearly fits the data better than the AR or LGC specifications. Consequently, it is worth the added complexity (i.e., estimated parameters) in the ALT specification in order to better capture important substantive explanations for longitudinal patterns in substance use and offending. The ALT model was assessed using alternate substantive specifications of the relationship between substance use and crime (e.g., cross-lagged effects, time-specific regression of criminal behavior on substance use), but all were found to have inferior fit compared to the model described here. The current specification includes correlations in the stage-specific substance use and crime measures and their growth factors.

The autoregressive simplex model derives estimates for direct effects (e.g., Time 2 on Time 1 offending), and the latent growth curve model captures five parameters associated with the latent growth factors (e.g., mean slope/intercept, variance of slope/intercept). The results of the ALT specification (Table 3 ) draw on both sets of estimates. In terms of the stage-to-stage (AR) effects, the substance use estimates are statistically significant at all years except the last." The standardized estimates for the significant effects are fairly steady across most time points $(.23-.33)$, but they do appear to get smaller at the last two stages, where they have values of .23 and .13, respectively. The effects for offending on itself are generally less stable and weaker across waves. Only four of the six estimates are statistically significant, ranging in magnitude from roughly .10 to .16 . The within-stage substance use-crime correlations are statistically significant and fairly sizeable for all years $(.20-.41)$.

The mean estimated slope is positive for substance use (.036) and negative for criminal activity (-.053). Both are slight in size--indicating fairly modest changes over time. The variance values for the crime intercept and slope are statistically significant, suggesting that there is between-individual variance among the parolees in terms of both the starting point of trajectories and their slopes across these

Table 2. Model Fit Statistics for Alt Model and Alternatives

\begin{tabular}{l|ccc}
\hline & \multicolumn{2}{c}{ Models } \\
& $\begin{array}{c}\text { Autoregressive/ } \\
\text { Simplex }\end{array}$ & Curve \\
\hline Model $\chi^{2}$ (df) & $381.87(72)^{*}$ & $345.65(84)^{*}$ & $127.77(62)^{*}$ \\
Log Likelihood & -8361.21 & -8170.26 & -8226.65 \\
Bayesian Information Criterion (BIC) & 17016.59 & 16905.26 & 16810.09 \\
Comparative Fit Index (CFI) & 0.91 & 0.93 & 0.99 \\
Tucker Lewis Index (TLI) & 0.89 & 0.92 & 0.98 \\
Root Mean Square Error Approx. (RMSEA) & 0.09 & 0.08 & 0.04 \\
Std. Root Mean Square Residual (SRMR) & 0.11 & 0.05 & 0.03 \\
\hline * $p<.05$ & & & A
\end{tabular}

WINTER 2010 


\section{Sullivan, Piquero}

Table 3. Key Maximum Likelihood Estimates for Alt Model ( $N=524)$

\begin{tabular}{|c|c|c|}
\hline & Est. (s.e.) & Sid. Est. \\
\hline $\begin{array}{l}\text { AR Estimates } \\
\text { Substance Use } Y 2 \text { on SU } Y 1 \\
\text { Substance Use } Y 3 \text { on SU } Y 2 \\
\text { Substance Use } Y 4 \text { on SU } Y 3 \\
\text { Substance Use } Y 5 \text { on SU } Y 4 \\
\text { Substance Use } Y 6 \text { on SU } Y 5 \\
\text { Substance Use } Y 7 \text { on SU } Y 6 \\
\text { Crime } Y 2 \text { on Crime } Y 1 \\
\text { Crime } Y 3 \text { on Crime } Y 2 \\
\text { Crime } Y 4 \text { on Crime } Y 3 \\
\text { Crime } Y 5 \text { on Crime } Y 4 \\
\text { Crime } Y 6 \text { on Crime } Y 5 \\
\text { Crime } Y 7 \text { on Crime } Y 6 \\
\text { SU } Y 1 \text { with Crime } Y 1 \\
\text { SU } Y 2 \text { with Crime } Y 2 \\
\text { SU } Y 3 \text { with Crime } Y 3 \\
\text { SU } Y 4 \text { with Crime } Y 4 \\
\text { SU } Y 5 \text { with Crime } Y 5 \\
\text { SU } Y 6 \text { with Crime } Y 6 \\
\text { SU } Y 7 \text { with Crime } Y 7\end{array}$ & $\begin{array}{l}.352(.054)^{*} \\
.296(.042)^{*} \\
.299(.035)^{*} \\
.301(.038)^{*} \\
.219(.048)^{*} \\
.128(.068) \\
.125(.049)^{*} \\
.044(.043) \\
.097(.036)^{*} \\
.158(.036)^{*} \\
.113(.042)^{*} \\
.048(.056) \\
.162(.037)^{*} \\
.096(.026)^{*} \\
.155(.025)^{*} \\
.185(.024)^{*} \\
.161(.025)^{*} \\
.114(.024)^{*} \\
.115(.027)^{*}\end{array}$ & $\begin{array}{l}.334 \\
.297 \\
.301 \\
.288 \\
.230 \\
.126 \\
.118 \\
.044 \\
.097 \\
.156 \\
.113 \\
.053 \\
.196 \\
.238 \\
.335 \\
.410 \\
.336 \\
.276 \\
.297\end{array}$ \\
\hline $\begin{array}{l}\text { LGC Estimates } \\
\text { SU Intercept Mean } \\
\text { SU Intercept Variance } \\
\text { SU Slope Mean } \\
\text { SU Slope Variance } \\
\text { Crime Intercept Mean } \\
\text { Crime Intercept Variance } \\
\text { Crime Slope Mean } \\
\text { Crime Slope Variance } \\
\text { SU Intrcpt/Slope Covariance } \\
\text { Crm Intrcpt/Slope Covariance } \\
\text { SU Intrcpt/Crm Intrcpt Cov } \\
\text { SU Intrcpt/Crm Slope Cov } \\
\text { SU Slope/Crm Intrcpt Cov } \\
\text { SU Slope/Crm Slope Cov }\end{array}$ & $\begin{array}{l}.911(.077)^{*} \\
.474(.090)^{*} \\
.036(.027) \\
.019(.004)^{*} \\
.859(.050)^{*} \\
.134(.037)^{*} \\
-.053(.015)^{*} \\
.011(.003)^{*} \\
-.022(.016) \\
-.025(.009)^{*} \\
.112(.027)^{*} \\
-.010(.007) \\
-.015(.007)^{*} \\
.008(.002)^{*}\end{array}$ & $\begin{array}{c}-. \\
-- \\
-- \\
-- \\
-- \\
-. \\
-- \\
-. \\
-.232 \\
-.657 \\
.444 \\
-.136 \\
-.303 \\
.585\end{array}$ \\
\hline $\begin{array}{l}\text { ALT Specific Estimates } \\
\text { SU } Y 1 \text { with SU Intercept } \\
\text { SU } Y I \text { with SU Slope } \\
\text { Crime } Y 1 \text { with Crm Intercept } \\
\text { Crime } Y 1 \text { with Crm Slope }\end{array}$ & $\begin{array}{l}.575(.076)^{*} \\
-.012(.021) \\
.072(.025)^{*} \\
.011(.007)\end{array}$ & $\begin{array}{l}.743 \\
-.076 \\
.269 \\
-.141\end{array}$ \\
\hline
\end{tabular}




\section{A Synthesized Model of Substance Use and Crime Trends}

years. Likewise, variance values for substance use growth factors are statistically significant, indicating that there is heterogeneity in this sample in terms of the initial level and longitudinal growth in that behavior. Like the stage-specific correlations, the substance use and crime latent growth factors are positively related. The standardized estimate of .44 for the substance use-crime intercept covariance suggests a moderate, positive relationship in initial levels of these behaviors. The standardized estimate of .58 for the slope covariance suggests substance use and crime tend to change in concert as well. ${ }^{12}$ Figure 3 shows the model estimated values for substance use and offending as compared to their respective, observed values. The plots clearly show very strong correspondence for the two, which again suggests that the ALT model provides a good fit to the data.

\section{Discussion}

Recognizing that a career perspective in substance use and crime research has emphasized both stability and change, and using longitudinal data for a large sample of California parolees, the present study employed a recently developed analytic approach, the autoregressive latent trajectory model (ALT), to analyze both persistent individual differences in behavioral trends and stage-specific direct relationships regarding criminal behavior and drug use. In framing the Autoregressive Latent Trajectory (ALT) model as a synthesis of two varied methodological approaches, Curran and Bollen (2001, p. 107) note that, "a critical comparative approach has

\section{Figure 3. Plot of Predicted and Sample-Observed Values for Alt Model}

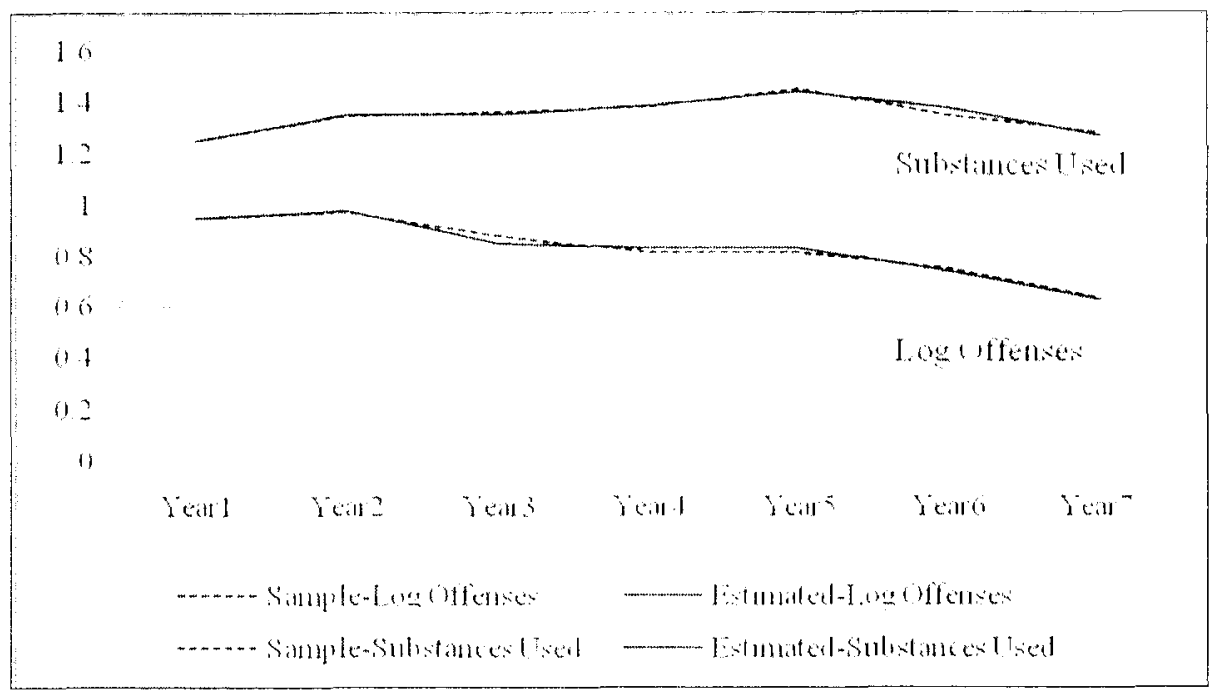




\section{Sullivan, Piquero}

tended to foster a polarization of views that has led many proponents of one modeling approach to reject the methods of the other, and vice versa." Fortunately, the use of the ALT model, in allowing for estimates of underlying, unfolding growth processes and stage-sequential direct effects of previous behavior, helps in addressing some key substantive questions that emerge in research on substance use and crime. ${ }^{13}$ In melding two analytic approaches, the model is uniquely situated to simultaneously examine the population heterogeneity and state-dependence views of stability and change in these behaviors.

The results of the analytic process suggest that the ALT model fit the data well. Comparatively, that model fit better than the autoregressive or LGC specifications and provides more information as well. The stage-sequential direct effects for substance use were generally positive and moderate, but there was less consistency in size and statistical significance for criminal activity. There was significant variation in the latent growth factors (intercept, slope) for both behaviors. This application also allows for an understanding of the joint development of those behaviors. Substance use and criminal behavior are positively correlated at each stage. The correlations across intercepts and slopes are also positive and sizeable for substance use and crime, suggesting the viability of jointly modeling their longitudinal trajectories.

The ALT model provides estimates that are relevant in understanding, both singly and jointly, key parameters of the substance use and criminal career frameworks. For example, in considering the life course of substance use as described by Hser et al. (2007), estimates from this model can provide insight on addiction across the career through the latent growth curve element of the model, and the intermittent abstinence and relapse process can be captured in the autoregressive portion. Similarly, the model can be useful in looking at key parameters of the criminal career (Blumstein et al., 1986; Piquero et al., 2003, 2007), such as persistence and desistance in offending. Additionally, the model provides a foundation for the incorporation of early risk factors that may be relevant to the longitudinal growth process (i.e., time-invariant effects) and also those that may be useful in understanding stagespecific effects (i.e., time-varying influences such as marriage or treatment). This is prominent in the work of Scott and colleagues (2005), which ties various static and dynamic factors to relapse and recovery in a sample of addicts, as well as that of Horney et al. (1995), which examined the impact of local life circumstances on short-term changes in offending. Additionally, consideration may be given to the manner in which social supports and influences interact with treatment services to impact substance use cessation and criminal desistance (Hser et al., 1997). These applications will, in turn, be relevant for discussions regarding the longitudinal relationship and concordance between crime and substance use, as well as the factors that relate to them individually and collectively. 


\section{A Synthesized Model of Substance Use and Crime Trends}

There is ample evidence of discontinuity in criminal behavior over time, of course (Laub \& Sampson, 2003), including the inconsistency of the estimates related to state dependence and the negative slope value in the present study. Similar patterns are evident in substance use careers in the form of cycles of abstinence and relapse (Dennis et al., 2007; Hser et al., 2007; Scott et al., 2005). As a result, it is important to focus on both within-individual differences over time and between-individual differences as a means of further elaborating theory and developing policy measures. Life-course perspectives in substance use and crime emphasize both turning points (i.e., change) and stability. One need only look at the number and nature of trajectory groups that have emerged from applications of the group-based trajectory modeling approach to longitudinal substance use (e.g., Chassin et al., 2004; Prendergast et al., 2008) and offending data (Bushway, Thornberry, \& Krohn, 2003; Nagin, Farrington, $\&$ Moffitt, 1995) to see that their respective career patterns are quite complex and require focus on both stability and change.

In a similar vein, the changing magnitude and significance of the specified statedependent effects identified here should be considered in conjunction with both life course and situational perspectives on substance use and offending (Horney et al., 1995). Commonly available approaches for dealing with time-varying covariates would prove useful in this endeavor (Osgood, 2010). Extant evidence suggests that development over the life course reflects some process emanating from within the person (i.e., population heterogeneity) in interaction with the social environment (i.e., state-dependent processes) where the two are believed to be "co-producers" (Featherman \& Lerner, 1985). Consequently, it is important that theoretical development and empirical research be directed at understanding propensity and social influence as they interact across the life course. For example, do certain situational influences wax and wane as time goes on-depending on individual propensity for antisocial behavior and the choices that individuals make that shape their social environment? Is the salience of these situational influences enhanced/ diminished at different stages of the life course? There must be greater theoretical elaboration and empirical investigation on the within-individual changes that might alter trajectories of substance use and offending. In addition, insights gleaned from life-course interdependence models (Wright, Caspi, Moffitt, \& Silva, 2001), with their focus on moderating relationships between criminal propensity and prosocial ties on crime, are likely to provide useful clues into the stability and change in both offending and substance use.

Overall, it is important to consider both long-term, enduring propensity and direct effects of behavior in terms of theory, policy, and treatment. In that sense, the ALT model can be particularly useful to the longitudinal study of substance use and crime, as it can capture a number of parameters of interest in illuminating 


\section{Sullivan, Piquero}

long-term behavioral trends. Individual treatment efforts must be informed by a mechanistic understanding of exactly how or why individual behavioral patterns change (or remain stable) (Farrington, 2005). The ALT model can help inform policy and practice because it allows for such understanding. For example, the ALT model could be used to better understand whether a particular intervention at one stage in time can loosen the continuity of substance use or delinquency - despite the cumulative effects of previous behavior and enduring propensity. Alternatively, the lack of a stage-specific effect might indicate that the effect of propensity prevails in influencing individual behavior over time. This would help guide responses to long-term substance use or criminal behavior.

The present study demonstrates the utility of using elements of both the LGC and autoregressive approach in studying behaviors from a "career" perspective. The fact that the integrated ALT model fit the data well suggests that the two views are compatible and necessary for explaining the life course of substance use and offending behavior. While the ALT model does provide further insight into our understanding of the continuity of substance use and criminal behavior, this study, and the model more generally, have limitations that need subsequent consideration.

Overall, further application of this model to important questions in developmental, life-course research is necessary to better understand the mechanisms underlying observed longitudinal patterns in behavior. One clear direction for future research is the incorporation of key explanatory factors, which, as mentioned earlier, may take the form of time-stable variables impacting the latent trajectory estimate and time-varying factors affecting the stage-sequential, autoregressive effects. Second, this application relied on several time points of data and was estimable as a result. In general, however, the identification considerations discussed by Bollen and Curran (2004) may not be attainable in data sets with fewer observation periods. Also, at present, the ALT model, as specified here, requires continuous data. Consequently, these analyses used a continuous dependent variable specification rather than a Poisson (Nagin \& Land, 1993; Prendergast et al., 2008) or a censored regression approach (Osgood, Finken, \& McMorris, 2002), which may better capture the nature of the outcomes studied here. These limitations again suggest that it is important that additional application and expansion of the ALT model is undertaken in an attempt to further assess its utility in understanding careers in substance use and offending.

Third, although the data utilized in this study captured several measurement periods, they do not persist deeply into the life course or capture earlier, juvenile offending and substance use. As a result there may be left or right "censoring" in the longitudinal patterns observed (Greenberg, 1991). Clearly, it would be useful to apply this approach to a sample with a longer time span to deal with the censoring issue and also potentially ameliorate the "initial condition" problem described earlier 


\section{A Synthesized Model of Substance Use and Crime Trends}

(Cameron \& Trivedi, 2005). Additionally, the data set utilized here is somewhat dated in terms of its time frame of initial collection and draws on official records for relatively serious offenders from a single state. Thus, this approach should be replicated in a more expansive pool of cases using a wider array of measures. As the current work draws on data from known offenders, it would be useful to apply this model to a general population sample to obtain a sense of its broader applicability. At the same time, practical application of the ALT model should be assessed with more time periods in order to assess its performance in situations where researchers have collected data on a panel for a lengthy span of time. It is possible that the increased number of parameter estimates required in such cases may alter model performance.

Finally, it is important that the study and explanation of long-term patterns of substance use and crime incorporate multiple perspectives on the source of behavioral continuity and change. Ideally, such studies will include theoretically relevant covariates. Analytic approaches such as the ALT model provide the flexibility necessary to obtain estimates for both state-dependence and population heterogeneity while also accommodating theoretically informed sources of explanation for longitudinal substance use and offending trends. In particular, the approach demonstrated here allows for a distilled summary of the career using the latent trajectory approach as well as a more localized perspective on the key relationships within the broader career. Further work along the lines suggested above will continue to spur important and useful descriptions of antisocial behavior and maintain relevance for theory and policy directed at both substance use and crime.

\section{Notes}

1. Data utilized in this study were drawn from Haapanen RA. Longitudinal study of criminal career patterns of former California youth authority wards, 19651984 [Computer file]. ICPSR version. Sacramento, CA: State of California, Department of the Youth Authority [producer], 1988. Ann Arbor, MI: Interuniversity Consortium for Political and Social Research [distributor], 1999. The author wishes to thank Jean McGloin, Richard Dembo, and David Greenberg for helpful comments on earlier drafts of this paper and Patrick Curran for clarification of a technical issue. The authors also wish to acknowledge helpful comments from the UCLA CALDAR faculty and two anonymous reviewers.

2. Although beyond the scope of this manuscript, these issues have been a source of much work in the criminological literature adjudicating between general, dynamic, and developmental models of crime (e.g., Gottfredson \& Hirschi, 1990; Moffitt, 1993; Paternoster \& Brame, 1997; Sampson \& Laub, 1993).

3. This limitation can be relaxed with the use of time-graded interaction terms (Osgood, 2010; Phillips \& Greenberg, 2008). 
4. In related work, Brame, Nagin, and Tremblay (2001) extended Nagin and Land's (1993) semiparametric, mixed Poisson (trajectory) model to study the development of different kinds of criminal activity, in their case, violent and non-violent crime. Clearly, their approach can be used to model distinct but related forms of behavior, such as involvement in crime and drugs.

s. Jöreskog (1970) provides further discussion on the identification and estimation of simplex models.

6. Bollen and Curran (2004) point out that this model specification is distinct from latent growth curves with autocorrelated errors between observed variables (see also, Brame, Mulvey, \& Piquero, 2001). The ALT model considers the relationship between both "explained" and "unexplained" portions of the repeated measures.

7. Bollen and Curran (2004) discuss the identifying conditions of these models with fewer waves of data. A limitation of the current data and model specification is the "initial condition" problem, which reflects a question of whether the analysis is truly capturing the process of interest at its initiation (Brame, Bushway, \& Paternoster, 1999). In the present case, the observations of substance use and offending begin after parole from custody so the true point of initiation of the behaviors is unlikely to be covered by these data.

8. Chi-square is a statistic that tests the degree of misfit between the modelhypothesized covariance matrix and the actual covariance matrix (Kline, 2005). A non-significant Chi-square suggests that the model fits the data adequately. The Comparative Fit Index $(C F I)$ and Tucker-Lewis Index $(T L I)$ are comparative fit measures that assess the proportionate improvement in fit through a comparison between the target model and a more restricted baseline model (i.e., "null model") (Hu \& Bentler, 1999; Kline, 2005). Like the Model Chi-Square, the Root Mean Square Error of Approximation (RMSEA) and Standardized Root Mean Square Residual (SRMR) are measures of absolute fit as they compare the specified model to one that reproduces the covariance matrix perfectly (i.e., focus on how well the model reproduces the data) (Hu \& Bentler, 1999). The RMSEA also adjusts for model complexity.

9. Although it is always best to utilize multiple indicators of model fit in trying to find the most appropriate model, the $B I C$ was the only fit measure available in this analysis that could directly arbitrate between model specifications. Although the AR and LGC are restricted components of a more general model (Curran \& Bollen, 2001), the fact that Substance Use ${ }_{t 1}$ and Crime ${ }_{\mathrm{tl}}$ were treated as "predetermined" here removes potential nesting of models, which precludes the use of likelihood ratio, or deviance, tests to assess improvement in fit across models (Bollen \& Curran, 2004). The BIC does draw on some of the same 
components used in the deviance test process, however (e.g., log-likelihood, number of free parameters).

10. Each model was also estimated with a control for time at risk during each year (see Piquero et al., 2001). Those results, although demonstrating poorer model fit, likely because the addition of street time as a regressor adds a number of estimates, largely confirm the key findings presented here. They are available from the first author upon request.

11. The individual parameter estimates for the two component models (not shown) were fairly similar to what was observed in ALT. This was the case for the latent growth factor estimates in particular. There was, however, a bit more stability in the observed autoregressive effect sizes in the model that did not contain the latent growth parameters (i.e., autoregressive only). This suggests that the observed relationship among the stage-sequential effects may be seen as stronger, and more consistent, than is actually the case when the latent growth factors (capturing enduring between-individual differences) are not included. This supports previous literature in this area that relies on other approaches (Bushway et al., 1999; Nagin \& Paternoster, 1991).

12. The issue of autocorrelated errors in like measures is of great importance in longitudinal modeling (Kessler \& Greenberg, 1981). The ALT model was specified with first order correlated errors to provide a preliminary assessment of the potential impact on key estimates. Although overall fit improved slightly, the added correlation values were inconsistent in their size and statistical significance. There was fairly little change to the size, direction, and significance in the ALT estimates presented here in this alternate model. These results are available from the first author upon request. See Bollen and Curran (2004) for more information on the treatment of autocorrelated errors in the ALT framework.

13. To be sure, even if the model presented here may be considered useful to the study of this topic, as Cohen and Vila (1996) point out, matters of contention in consideration of career perspectives are unlikely to be settled with the mere, "application of more powerful statistical tools" (p.148). This is further evidenced in more recent debates in the criminological literature regarding issues that cross conceptual/methodological lines (Kreuter \& Muthén, 2008; Nagin \& Tremblay, 2005a, 2005b; Raudenbush, 2005; Sampson \& Laub, 2005a, 2005b). 


\section{References}

Anglin, D.M., \& Speckart, G.

1986 Narcotics use, property crime, and dealing: Structural dynamics across the addiction career. Journal of Quantitative Criminology, 2, 355-375.

Ball, J.C., Rosen, L., Flueck, J.A., \& Nurco, D.N.

1981 The criminality of heroin addicts: When addicted and when off opiates. In J.A. Inciardi (Ed.), The drugs-crime connection (pp. 39-66). Beverly Hills, CA: Sage.

Bergman, L.R., \& Magnusson, D.

1997 Aperson-oriented approach to research on developmental psychopathology. Development and Psychopathology, 9, 291-319.

Blumstein, A., Cohen, J., Roth, J.A., \& Visher, C.

1986 Criminal careers and "career criminals" (Vol. I). Washington, DC: National Academy Press.

Bollen, K.A, \& Curran, P.J.

2004 Autoregressive latent trajectory (ALT) models: A synthesis of two traditions. Sociological Methods and Research, 32, 336-383.

Brame, R., Bushway, S., \& Paternoster, R.

1999 On the use of panel research designs and random effect models to investigate static and dynamic theories of criminal offending. Criminology, 37, 599641.

Brame, R., Mulvey, E.P., \& Piquero, A.

2001 On the Development of Different Kinds of Criminal Activity. Sociological Methods and Research 29:319-341.

Brame, R., Nagin, D., \& Tremblay, R.

2001 Developmental trajectories of physical aggression from school entry to late adolescence. Journal of Child and Adolescent Psychology, 42, 503512.

Brame, R., Nagin, D.S., \& Wasserman, L.

2006 Exploring some analytic characteristics of finite mixture models. Journal of Quantitative Criminology, 22, 31-59.

Bushway, S., Brame, R., \& Paternoster, R.

1999 Assessing stability and change in criminal offending: A comparison of random effects, semiparametric, and fixed effects modeling strategies. Journal of Quantitative Criminology, 15, 23-61.

Bushway, S., Thornberry, T., \& Krohn, M.

2003 Desistance as a developmental process: A comparison of static and dynamic approaches. Journal of Quantitative Criminology, 19, 129-153. 


\section{A Synthesized Model of Substance Use and Crime Trends}

Cameron, A.C., \& Trivedi, P.K.

2005 Microeconometrics: Methods and applications. Cambridge, UK: Cambridge University.

Chaiken, J.M., \& Chaiken, M.R.

1982 Varieties of criminal behavior. Santa Monica, CA: Rand.

Chaiken, J.M., \& Chaiken, M.R.

1990 Drugs and predatory crime. In M. Tonry \& J.Q. Wilson (Eds.), Drugs and crime (pp. 203-239). Chicago, IL: University of Chicago.

Chassin, L., Flora, D.B., \& King, K.M.

2004 Trajectories of alcohol and drug use and dependence from adolescence to adulthood: The effects of familial alcoholism and personality. Journal of Abnormal Psychology, 113, 483-493.

Chung, T., Maisto, S.A., Cornelius, J.R., \& Martin, C.S.

2004 Adolescents' alcohol and drug use trajectories following treatment. Journal of Studies on Alcohol, 65, 105-114.

Clayton, R.R., \& Tuchfeld, B.S.

1982 The drug-crime debate: Obstacles to understanding the relationship. Journal of Drug Issues, 12, 153-166.

Cohen, L.E., \& Vila, B.J.

1996 Self-control and social control: An exposition of the Gottfredson-Hirschi/ Sampson-Laub debate. Studies on Crime and Crime Prevention, 5, 125150.

Curran, P.J., \& Bollen, K.A.

2001 The best of both worlds: Combining autoregressive and latent curve models. In L.M. Collins \& A. Sayer (Eds.), New methods for the analysis of change (pp. 107-135). Washington, DC: American Psychological Association.

Da Agra, C.

2002 The complex structures, processes and meanings of the drug/crime relationship. In S. Brochu, C. Da Agra, \& M.M. Cousineau (Eds.), Drug and crime deviant pathways (pp. 9-32). Burlington, VT: Ashgate.

Dennis, M.L., Foss, M.A., \& Scott, C.K.

2007 An eight-year perspective on the relationship between the duration of abstinence and other aspects of recovery. Evaluation Review, 31, 585-612.

Dennis, M.L., Scott, C.K., Funk, R., \& Foss, M.A.

2005 The duration and correlates of addiction and treatment careers. Journal of Substance Abuse Treatment, 28, S51-S62. 


\section{Sullivan, Piquero}

Farabee, D., Joshi, V., \& Anglin, D.M.

2001 Addiction careers and criminal specialization. Crime and Delinquency, 47, 196-220.

Farrington, D.P.

2005 Introduction to integrated developmental and life-course theories of offending. In D.P. Farrington (Ed.), Advances in criminological theory (Vol. 14): Integrated developmental and life-course theories of offending (pp. 1-14). New Brunswick, NJ: Transaction.

Featherman, D., \& Lerner, R.

1985 Ontogenesis and sociogenesis: Problematics for theory and research about development and socialization across the lifespan. American Sociological Review, 50, 659-676.

Gottfredson, M.R., \& Hirschi, T.

1990 A general theory of crime. Palo Alto, CA: Stanford.

Greenbaum, P.E., Del Boca, F.K., Darkes, J., Wang, C.P., \& Goldman, M.

2005 Variation in the drinking trajectories of freshman college students. Journal of Consulting and Clinical Psychology, 73, 229-238.

Greenberg, D.F.

1991 Modeling criminal careers. Criminology, 29, 17-46.

Greene, W.H.

2003 Econometric analysis (5th ed.). Upper Saddle River, NJ: Prentice Hall.

Haapanen, R.

1990 Selective incapacitation and the serious offender: $A$ longitudinal study of criminal career patterns. New York: Springer-Verlag.

Hancock, G., \& Lawrence, F.

2006 Using latent growth models to evaluate longitudinal change. In G. Hancock

\& R. Mueller (Eds.), Structural equation modeling: A second course (pp.

171-196). Greenwich, CT: Information Age Publishing.

Heckman, J.J.

1981 Statistical models for discrete panel data. In C.F. Manski \& D. McFadden (Eds.), Structural analysis of discrete data with econometric applications (pp. 114-178). Cambridge, MA: MIT Press.

Horney, J.D., Osgood, D.W., \& Marshall, I.H.

1995 Criminal careers in the short-term: Intra-individual variability in crime and its relation to local life circumstances. American Sociological Review, $60,655-673$.

Hser, Y.I., Anglin, M.D., Grella, C., Longshore, D., \& Prendergast, M.L.

1997 Drug treatment careers: A conceptual framework and existing research findings. Journal of Substance Abuse Treatment, 14, 543-558. 
Hser, Y.I., Hoffman, V., Grella, C., \& Anglin, M.D.

2001 A 33-year follow-up of narcotics addicts. Archives of General Psychiatry, 58, 503-508.

Hser, Y.I., Longshore, D., \& Anglin, M.D.

2007 The life course perspective on drug use: A conceptual framework for understanding drug use trajectories. Evaluation Review, 31, 515-547.

Hu, L., \& Bentler, P.M.

1999 Cut off criteria for fit indexes in covariance structure analysis: Conventional criteria versus new alternatives. Structural Equation Modeling, 6, 1-55.

Hunt, D.E.

1997 A selected bibliography of the substance use(r) career. Substance Use and Misuse, 32, 283-291.

Hussong, A.M., Curran, P.J., Moffitt, T.E., Caspi, A., \& Carrig, M.M.

2004 Substance abuse hinders desistance in youth adults' antisocial behavior. Development and Psychopathology, 16, 1029-1046.

Jöreskog, $\mathrm{K}$.

1970 Estimation and testing of simplex models. British Journal of Mathematical Statistics in Psychology, 23, 121-145.

Kessler, R.C., \& Greenberg, D.F.

1981 Linear panel analysis: Models of quantitative change. New York: Academic Press.

Kline, R.B.

2005 Principles and practices of structural equation modeling ( $2^{\text {nd }}$ ed.). New York: Guilford.

Kreuter, F., \& Muthén, B.

2008 Analyzing criminal trajectory profiles: Bridging multilevel and groupbased approaches using growth mixture modeling. Journal of Quantitative Criminology, 24, 1-32.

Laub, J.H., Nagin, D.S., \& Sampson, R.J.

1998 Trajectories of change in criminal offending: Good marriages and the desistance process. American Sociological Review, 63, 225-238.

Laub, J.H., \& Sampson, R.J.

2001 Understanding desistance from crime. In M. Tonry (Ed.), Crime and justice: A review of research (Vol. 28, pp. 1-69). Chicago, IL: University of Chicago.

Laub, J.H., \& Sampson, R.J.

2003 Shared beginnings, divergent lives: Delinquent boys to age 70. Cambridge, MA: Harvard. 


\section{Sullivan, Piquero}

LeBlanc, M., \& Loeber, R.

1998 Developmental criminology updated. In M. Tonry (Ed.), Crime and justice (Vol. 23, pp. 115-198). Chicago, IL: University of Chicago.

Loeber, R., \& LeBlanc, M.

1990 Toward a developmental criminology. In M. Tonry \& N. Morris (Eds). Crime and justice (Vol. 12, pp. 375-473). Chicago, IL: University of Chicago

Marsh, H.W.

1993 Stability of individual differences in multi-wave panel studies: Comparison of simplex models and one factor models. Journal of Educational Measurement, 30, 157-183.

McGlothlin, W.H., Anglin, D.M., \& Wilson, B.D.

1978 Narcotics addiction and crime. Criminology, 16, 293-315.

Moffitt, T.E.

1993 Adolescent-limited and life-course-persistent antisocial behavior: A developmental taxonomy. Psychological Review, 100, 674-701.

Muthén, B.O., \& Muthén, L.K.

1998-2008 Mplus user's guide (5th ed.). Los Angeles, CA: Muthén \& Muthén.

Nagin, D.S.

2005 Group-based modeling of development. Cambridge, MA: Harvard.

Nagin, D.S., Farrington, D.P, \& Moffitt, T.E.

1995 Life course trajectories of different types of offenders. Criminology, 33, 111-139.

Nagin, D.S., \& Land, K.

1993 Age, criminal careers, and population heterogeneity: Specification and estimation of a nonparametric, mixed Poisson model. Criminology, 31, 327-362.

Nagin, D.S., \& Paternoster, R.

1991 On the relationship of past to future delinquency. Criminology, 29, 163189.

Nagin, D.S., \& Paternoster, R.

2000 Population heterogeneity and state dependence: State of the evidence and directions for future research. Journal of Quantitative Criminology, 16, 117-144.

Nagin, D.S., \& Tremblay, R.E.

2005a What has been learned from group-based trajectory modeling? Examples from physical aggression and other problem behaviors. Annals of the American Academy of Political and Social Sciences, 602, 82-117. 


\section{A Synthesized Model of Substance Use and Crime Trends}

Nagin, D.S., \& Tremblay, R.E.

2005b Developmental trajectory groups: Fact or a useful statistical fiction? Criminology, 43, 873-903.

Nielsen, A.L.

1999 Testing Sampson and Laub's life course theory: Age, race/ethnicity, and drunkenness. Deviant Behavior, 20, 129-151.

Nurco, D.N., Cisin, I., \& Mitchell, B.

1981 Addict careers I: A new typology. International Journal of the Addictions, 16, 1305-1325.

Nurco, D.N., Hanlon, T.E., Kinlock, T.W., \& Duszynski, K.R.

1988 Differential criminal patterns of narcotic addicts over an addiction career.

Criminology, 26, 407-423.

Osgood, D.W.

2010 Statistical models of life events and criminal behavior. In A.R. Piquero \& D. Weisburd (Eds.), The handbook of quantitative criminology. New York: Springer, pp. 375-396.

Osgood, D.W.

2005 Making sense of crime and the life-course. Annals of the American Academy of Political and Social Sciences, 602, 196-211.

Osgood, D.W., Finken, L.W., \& McMorris, B.

2002 Analyzing multiple-item measures of crime and deviance II: Tobit regression analysis of transformed scores. Journal of Quantitative Criminology, 18, 319-347.

Osgood, D.W., Johnston, L.D., O'Malley, P.M., \& Bachman, J.G.

1988 The generality of deviance in late adolescence and early adulthood. American Sociological Review, 53, 81-93.

Paternoster, R., \& Brame, R.

1997 Multiple routes to delinquency? A test of development and general theories of crime. Criminology, 35, 49-84.

Phillips, J.A., \& Greenberg, D.F.

2008 A comparison of methods for analyzing criminological panel data. Journal of Quantitative Criminology, 24, 51-72.

Piquero, A.R.

2008 Taking stock of developmental trajectories of criminal activity over the life course. In A. Liberman (Ed.), The long view of crime: A synthesis of longitudinal research (pp. 23-78). New York: Springer. 
Piquero, A.R., Blumstein, A., Brame, R., Haapanen, R., Mulvey, E., \& Nagin, D.S. 2001 Assessing the impact of exposure time and incapacitation on longitudinal trajectories of criminal offending. Journal of Adolescent Research, 16, 5474.

Piquero, A.R., Brame, R., Mazerolle, P., \& Haapanen, R.

2002 Crime in emerging adulthood. Criminology, 40, 137-169.

Piquero, A.R., Farrington, D.P., \& Blumstein, A.

2003 The criminal career paradigm: Background and recent developments. In M. Tonry (Ed.), Crime and justice: A review of research (Vol. 30, pp. 359506). Chicago, IL: University of Chicago.

Piquero, A.R., Farrington, D.P., \& Blumstein, A.

2007 Key issues in criminal career research: New analyses of the Cambridge Study in Delinquent Development. Cambridge, UK: Cambridge University Press.

Piquero, A.R., MacDonald, J., \& Parker, K.

2002 Race, local life circumstances, and criminal activity. Social Science Quarterly, 3, 654-670.

Prendergast, M.D., Huang, D., \& Hser, Y.I.

2008 Patterns of crime and drug use trajectories in relation to treatment initiation and 5-year outcomes: An application of growth mixture modeling across three data sets. Evaluation Review, 32, 59-82.

Raudenbush, S.W.

2005 How do we study "what happens next"? Annals of the American Academy of Political and Social Sciences, 602, 131-144.

Robins, L.N.

1978 Sturdy childhood predictors of adult antisocial behavior: Replications from longitudinal studies. Psychological Medicine, 8, 611-622.

Sampson, R.J., \& Laub, J.H.

1993 Crime in the making: Pathways and turning points through life. Cambridge, MA: Harvard.

Sampson, R.J., \& Laub, J.H.

2005a A life-course view of the development of crime. Annals of the American Academy of Political and Social Sciences, 602, 12-45.

Sampson, R.J., \& Laub, J.H.

2005b Seductions of method: Rejoinder to Nagin and Tremblay. Criminology, 43, 905-913.

Scott, C.K., Foss, M.A., \& Dennis, M.L.

2005 Pathways in the relapse - treatment-recovery cycle over 3 years. Journal of Substance Abuse Treatment, 28, S63-72. 
A Synthesized Model of Substance Use and Crime Trends

Shaw, V.

2002 Substance use and abuse: A career perspective. Addiction Research and Theory, 10, 501-534.

Singer, J.D., \& Willett, J.B.

2003 Applied longitudinal data analysis: Modeling change andevent occurrence. New York: Oxford University.

Wright, B.E., Caspi, A., Moffitt, T.E., \& Silva, P.

2001 The effects of social ties on crime vary by criminal propensity: A lifecourse model of interdependence. Criminology, 39, 321-351. 